\section{ABCS}

How to cite this article: Almeida et al. Incidence of clinical and subclinical macular edema in patients submitted to phacoemulsification in a university health service. ABCS Health Sci. 2020;45(Suppl.3):e020103. https://doi. org/10.7322/abcshs.2020S03.1850

Corresponding Author: Vagner Loduca Lima - Discipline of Ophthalmology, Centro Universitário - Avenida Lauro Gomes, 2000 - Sacadura Cabral - CEP: 09060-650 - Santo André (SP), Brazil -

E-mail: vagner@loduca.com.br

Declaration of interests: nothing to declare

This is an open access article distributed under the terms of the Creative Commons Attribution License

(C) 2020 Almeida et al.

\title{
Incidence of clinical and subclinical macular edema in patients submitted to phacoemulsification in a university health service
}

\author{
Luciana de Almeida1, Glaucia Luciano da Veiga ${ }^{1,2}$, Fernando Martins de Oliveira ${ }^{1}$, \\ Fernando Luiz Affonso Fonseca ${ }^{1,2,3}$, Vagner Loduca Lima ${ }^{1}$, Júlio Zaki Abucham Neto ${ }^{1}$ \\ ${ }^{1}$ Discipline of Ophthalmology, Centro Universitário FMABC - Santo André (SP), Brazil \\ ${ }^{2}$ Clinical Analysis Laboratory, Centro Universitário FMABC - Santo André (SP), Brazil \\ ${ }^{3}$ Department of Pharmaceutical Sciences, Universidade Federal de São Paulo (UNIFESP) - \\ Diadema (SP), Brazil.
}

\begin{abstract}
Introduction: The incidence of cystoid macular edema (CME) after cataract surgery varies substantially and depending on the diagnostic method used. In addition, other factors that influence the incidence of CME are the technique of surgery and the associated comorbidities. Objective: The aim of the present study was to evaluate the incidence of EMC after uncomplicated phacoemulsification surgery, using the spectral domain optical coherence tomography (OCT). Methods: The incidence of subclinical and clinical CME was evaluated in 14 patients who underwent uncomplicated phacoemulsification surgery, using OCT before the surgical procedure and after seven and 28 days after it. The volunteers could not use a prostaglandin analogue or present any retinopathy that compromised visual acuity. Results: The incidence of clinically significant CME was 6.4\%, however retinal thickening by OCT was observed in all patients in the fourth postoperative week. Regarding gender and laterality, the percentages were similar. Conclusion: In this study, we obtained a low incidence of EMC in patients assisted at this center, corroborating multicenter studies.
\end{abstract}

Keywords: cystoid macular edema; phacoemulsification; cataract; post-surgical.

\section{INTRODUCTION}

Cystoid Macular Edema remains the most frequent cause of low vision after cataract surgery ${ }^{1,2}$. Despite advances in cataract surgery, such as microincision and new phacoemulsification techniques, CME can occur even in the absence of complications ${ }^{3}$. This develops due to the breakdown of the hematoretinal barrier, causing accumulation of fluid in the extracellular space of the retina and formation of cysts in the external plexiform and internal nuclear layers ${ }^{4,5}$.

The incidence of CME varies substantially in the literature depending on the diagnostic method used. For such detection, clinical examination, angiographic examination or optical coherence tomography (OCT) examination can be performed. In increasing order of sensitivity for detection of CME we have: OCT, followed by angiography and then clinical examination. Therefore, the incidence of EMC after phacoemulsification varies depending 
on which technique is used. Studies have shown an incidence of CME measured by OCT after cataract surgery of up to 41 percent on average, while for angiofluoresceinography it had an average of 30 percent. The incidence of clinically relevant CME, when there is low visual acuity, varied between $1 \%$ and $2 \%$, depending on the study ${ }^{6}$.

In addition to the diagnostic method used, other factors that influence the incidence of CME after cataract surgery are the technique of the surgery and the associated comorbidities ${ }^{1,2,7-10}$.

The pathogenesis of CME after phacoemulsification is multifactorial according to experimental and clinical observational studies $^{10}$. Etiological factors include inflammation, vitreous traction and hypotonia ${ }^{11-13}$. Among them, the main mechanism responsible is the inflammation of the anterior segment that results from the release of inflammatory chemical mediators such as prostaglandins, cytokines, anti-VEGF and other factors, which increase the capillary permeability of the perifoveal retina, resulting in the accumulation of fluid in the layers external plexiform and internal nuclear ${ }^{13}$.

The main preoperative risk factors for CME are previous retinal diseases, such as venous occlusions, diabetic retinopathy and changes in the vitreoretinal interface (epiretinal membrane, vitreous-macular traction syndrome, etc.)5. In the case of diabetic retinopathy, it is difficult to differentiate CME from the progression of diabetic macular edema since these patients tend to worsen their edema after the facectomy ${ }^{14,15}$. Other risk factors include uveitis, glaucoma, use of prostaglandin eye drops, or use of eye drops whose preservative is benzalkonium chloride ${ }^{14-16}$.

In the perioperative period, the main risk factors are irian trauma, posterior capsule rupture and, mainly, vitreous loss ${ }^{15-18}$.

For diagnostic purposes of pseudophakic cystoid macular edema, OCT has been gaining ground due to its high sensitivity, in addition to having the advantages of not being invasive, being more comfortable and safer than fluorescein angiography, which allows its frequent repetition. Furthermore, it offers a quantitative assessment, allowing a verification of disease progression and treatment effectiveness ${ }^{18}$.

Subclinical macular edema can develop even after uncomplicated cataract surgery and in non-predisposed patients. It has been shown that OCT is a method capable of detecting small increases in macular thickness, which may not be detected on clinical examination, allowing its early treatment, to avoid, whenever possible, loss of visual acuity ${ }^{19,20}$.

The aim of the present study is to assess the incidence of subclinical and clinical EMC after uncomplicated phacoemulsification surgery, using optical coherence tomography. The secondary objective is to correlate the presence of EMC with the amount of ultrasound used during the procedure.

\section{METHODS}

After approval by the Ethics and Research Committee of the Centro Universitário FMABC, an observational and prospective study was conducted in which 15 eyes of 14 patients who underwent cataract surgery were evaluated. Only volunteers who met the inclusion criteria participated in the work and agreed to sign the informed consent form. Inclusion criteria: signed informed consent form; OCT with an exam score greater than or equal to 7; age greater than 50 years; patients who wish and are able to carry out return visits during the study period. Exclusion criteria: any retinopathy that causes low visual acuity; presence of macular edema in the control OCT; cataract surgery other than phacoemulsification; eye surgery performed in the last 180 days; any perioperative complication; use of a prostaglandin analogue; previous treatment of macular edema in the operated eye.

In the preoperative and postoperative exams at 1 and 4 weeks, the following exams were performed: visual acuity with correction measured in the Snellen table, slit lamp biomicroscopy, fundoscopy and the OCT Spectral Domain (Heidelberg Spectralis ${ }^{\circledR}$ ENGINEERING) in a spotless way FAST.

The surgeries were performed by ophthalmologists with the same level of experience, and the materials used were standardized in the same concentration (bupivacaine, adrenaline and carbacol for intracameral use). The surgical technique used was phacoemulsification and the intensity of ultrasound in metrics and the time in each surgical procedure were measured. The eye drops prescribed after surgery were predinisolone $1 \%$ at similar weaning in the first 28 days and gatifloxacin $0.3 \%$ in the first 7 postoperative days. From this, the following data were collected: age, gender, laterality, corrected visual acuity before surgery (CVA/BS), corrected visual acuity after 1 week of surgery (CVA/A1W), corrected visual acuity after 4 weeks of surgery (CVA/A4W), time, ultrasound intensity used (UIU), macular central thickness of 1 $\mathrm{mm}$ in diameter measured by the OCT before, after 1 week and after 4 weeks of surgery. Correlations were made with the above data and the incidence of CME in this sample was evaluated. In addition, patients were divided into three groups according to the UIU in each surgery ( 0 to 5 metrics - Group 1, between 5 and 10 metrics - Group 2; and greater than 10 metrics - Group 3), and the incidence was evaluated of clinical and subclinical CME in each group.

The data were presented in absolute values and percentage, mean and standard deviation of the mean. Spearman's test was applied for correlation analysis. To evaluate the statistical differences, the GraphPad Prism ${ }^{\circledR}$ software version 6.0 was used. Values were considered statistically significant when $\mathrm{p}<0.05$.

\section{RESULTS}

The study included 15 eyes of 14 patients operated on for 8 months, with each patient being followed for at least 1 month.

The main characteristics of the volunteers are shown in Table 1. The average age was 69.8 years, ranging from 59 to 83 years. The 
percentage of female patients (53\%) was close to the percentage of male patients (47\%).

The average time to perform the surgeries was $21 \pm 12$ minutes. Regarding UIU, the average was 4.48 metrics, ranging from 1.41 to 16 metrics.

The mean CVA/BS was lower (0.52) than the average CVA/ A1W (0.79) and CVA/A4W (0.9) as shown in Table 2. We observed that the values of CVA/BS were not correlated with postsurgical time (Table 3).

It was observed that the incidence of clinical macular edema was $9 \%(1 / 11)$ in Group 1 and absent in the other groups and was only present in the examination in the fourth postoperative week. Regarding subclinical macular edema, it was absent in all groups in all evaluations. There was a slight increase in macular thickness in all evaluations in the fourth week after surgery, with an average increase of $4.8 \%$. However, in the 1 -week postoperative period (1WPP), some patients presented a decrease in macular thickness while others presented macular thickening, with the thickness value in the last few days being less than the value of the fourth week (4WPP).

The general incidence of clinical macular edema after cataract surgery was $6.7 \%(1 / 15)$. Low visual acuity was the main manifestation of the disease and intra-retinal fluid associated with an increase in retinal thickness in SD-OCT by $26 \%$ (286 pre-operative central microns to 362 post-operative central microns) confirmed the pathology. The other patients did not complain of low visual acuity or the presence of intra and/or subretinal fluid.

Regarding follow-up, the patient who presented with clinical macular edema underwent treatment with topical corticosteroid eye drops in regression associated with non-steroidal anti-inflammatory eye drops according to the service protocol, showing improvement in visual acuity and image in the SD-OCT. In the second month of treatment, the patient showed total regression of intraretinal fluid and a decrease in central macular thickness by $20 \%$ (298 microns). During the 3-month follow-up after treatment, he did not have a recurrence of the edema.

\section{DISCUSSION}

In fact, the onset of CME after a facectomy is typically 4 to 12 weeks after surgery, and in this study we opted to perform OCT in the fourth week and also the first postoperative week to better assess the incidence of subclinical $\mathrm{CME}^{10}$.

We report a general incidence of SMC of $6.4 \%$, with only clinical SMC present, which is consistent with other studies ${ }^{21,22}$. To date, the study of the incidence of CME after phacoemulsification without complications has not been carried out in this school service, demonstrating its importance.

Table 1: Anthropometric data. Data expressed as percentage and average $\pm S D$.

\section{Parameters}

$\operatorname{Sex}(\%)$

Eye $(\%)$
Age (average $\pm S D$ )

$n=15$
$69.8 \pm 7.8$ years

\begin{tabular}{c|c|}
\hline Women & 53 \\
\hline Men & 47 \\
\hline Right & 47 \\
\hline Left & 53 \\
\hline
\end{tabular}

Table 2: Data related to surgical time and metrics. CAV/BS - visual acuity with preoperative correction; CAV/A1W - visual acuity with correction after 1 week of surgery; CAV/A4W - visual acuity with correction after 4 weeks of surgery. Data expressed as mean \pm SD.

\begin{tabular}{|c|c|}
\hline Parameters & Values (average \pm SD) \\
\hline Time $(\min )$ & $21 \pm 12$ \\
\hline Metrics & $4.48 \pm 3.49$ \\
\hline CAV/BS & $0.52 \pm 0.18$ \\
\hline CAV/A1W & $0.79 \pm 0.22$ \\
\hline CAV/A4W & $0.90 \pm 0.15$ \\
\hline
\end{tabular}

Table 3: Correlation data between CAV/BS versus CAV/A1W and CAV/A4W. CAV/BS - visual acuity with preoperative correction; CAV/A1W - visual acuity with correction after 1 week of surgery; CAV/A4W - visual acuity with correction after 4 weeks of surgery. Data expressed as mean \pm SD.

\begin{tabular}{|l|c|c|}
\hline & CAV/A1W & AV/A4W \\
\hline & $r^{2}$ & $r^{2}$ \\
\hline CAV/BS & 0.0920 & -0.232 \\
\hline$p$ & 0.744 & 0.405 \\
\hline
\end{tabular}

In the OCT exam in the fourth week, the presence of mild central macular thickening was contacted in all patients, whereas in 1WPP there were no variations between mild thickening and slight thickness decrease. It was found that in 4WPP the macular thickness was always greater than in 1WPP. Regarding the analysis of risk factors, there was no correlation between the presence of edema with the surgical time or with the intensity of the ultrasound, which can be explained by the small number of patients.

No worsening of visual acuity was observed in any patient in the 1WPP, even in those who had retinal thickening in this assessment. In the study by Perente et al..$^{22}$ it has been reported that the increase in macular thickness after cataract surgery remains mainly at the subclinical level and does not affect visual acuity, which is consistent with our study. In addition, they showed that after uncomplicated phacoemulsification surgery, an increase in macular thickness it was visible in others in the peri-oval sites.

Regarding follow-up, the patient with CME did not present a relapse for 3 months after the end of treatment. In a study by Daien et al. ${ }^{23}$ with 19,980 eyes, the average duration of the edema was 2.8 months and only $9.4 \%$ of the patients had CME lasting from 6 to 12 months, corroborating that the disease is chronic in a small percentage of cases. 
It is known that the presence of diabetes is a risk factor for CME, especially in patients with diabetic retinopathy or with a history of diabetic macular edema ${ }^{24-27}$.

In our study, a patient with mild diabetic retinopathy did not have CME disagreeing with the studies above, which can be justified by the small number of diabetics in the study.

First, the risk factors for a relatively rare disease are difficult to estimate. In addition, the incidence may have been underestimated as the second exam took place over an average period of 1 week and 4 weeks on the third exam. It is known that the peak incidence of the pathology is in the sixth week, however the fourth week was chosen because of the ease of monitoring the patient in the routine of the outpatient service of the cataract service. It is possible that some patients do not have edema on the day of the examination but have had it before or after. The patient in the study who developed CME reported a symptom of low visual acuity on the fourth week and presented retinal tomographic alteration, which did not happen in the first week. Fundscopy showed no significant changes assessed by the examiner, which demonstrates the benefit of performing the SD-OCT for diagnosing the pathology.

\section{Conclusion}

Our combined data showed the incidence of CME in uncomplicated cataract surgeries at the Center for Ophthalmology Studies at Centro Universitário FMABC. In this study, we obtained a low incidence of CME in patients assisted at this center, corroborating multicenter studies. We believe that these data are preliminary and that it will be necessary to evaluate a larger number of patients to characterize more accurately the incidence of this disease in this region.

\section{REFERENCES}

1. Nelson ML, Martidis A. Managing cystoid macular edema after cataract surgery. Curr Opin Ophthalmol. 2003;14(1):39-43. https://doi.org/10.1097/00055735-200302000-00007

2. Ray S, D'Amico DJ. Pseudophakic cystoid macular edema. Semin Ophthalmol. 2002;17(3-4):167-80. https://doi.org/10.1076/soph.17.3.167.14794

3. Belair ML, Kim SJ, Thorne JE, Dunn JP, Kedhar SR, Brown DM, et al. Incidence of cystoid macular edema after cataract surgery in patients with and without uveitis using optical coherence tomography. Am J Ophthalmol. 2009;148(1):128-35.e2. https://doi.org/10.1016/j.ajo.2009.02.029

4. Irvine SR. A newly defined vitreous syndrome following cataract surgery. Am J Ophthalmol. 1953;36(5):599-619. https://doi.org/10.1016/0002-9394(53)90302-х

5. Gass JD, Norton EW. Cystoid macular edema and papilledema following cataract extraction. A fluorescein fundoscopic and angiographic study. Arch Ophthalmol. 1966;76(5):646-61. https://doi.org/10.1001/archopht.1966.03850010648005

6. Henderson BA, Kim JY, Ament CS, Ferrufino-Ponce ZK, Grabowska A, Cremers SL. Clinical pseudophakic cystoid macular edema. Risk factors for development and duration after treatment. J Cataract Refract Surg. 2007:33(9):1550-8. https://doi.org/10.1016/j.jcrs.2007.05.013

7. Mentes J, Erakgun T, Afrashi F, Kerci G. Incidence of cystoid macular edema after uncomplicated phacoemulsification. Ophthalmologica. 2003;217(6):408-12 https://doi.org/10.1159/000073070

8. Kim SJ, Equi R, Bressler NM. Analysis of macular edema after cataract surgery in patients with diabetes using optical coherence tomography. Ophthalmology. 2007;114(5):881-9. https://doi.org/10.1016/j.ophtha.2006.08.053

9. Lally DR, Shah CP. Pseudophakic Cystoid Macular Edema. Pseudophakic CME remains a common cause of reduced vision after cataract surgery. A look at its causes and treatment. Rev Ophthalmol. 2014
10. Flach AJ. The incidence, pathogensis and treatment of cystoid macular edema following cataract surgery. Trans Am Ophthalmo Soc 1998;96:557-634

11. Jampol LM. Aphakic cystoid macular edema. A hypothesis. Arch Ophthalmol. 1985;103(8):1134-5. https://doi.org/10.1001/archopht.1985.01050080046017

12. Reese AB, Jones IS, Cooper WC. Macular changes secondary to vitreous traction. Trans Am Ophthalmol Soc. 1966;64:123-34.

13. Yonekawa Y, Kim IK. Pseudophakic cystoid macular edema. Curr Opin Ophthalmol. 2012;23(1):26-32. https://doi.org/10.1097/ICU.0b013e32834cd5f8

14. Diabetic Retinopathy Clinical Research Network Authors/Writing Committee; Baker CW, Almukhtar T, Bressler NM, Glassman AR, Grover S, et al. Macular edema after cataract surgery in eyes without preoperative central-involved diabetic macular edema. JAMA Ophthalmol. 2013;131(7):870-9. https://doi.org/10.1001/jamaophthalmol.2013.2313

15. Arcieri ES, Santana A, Rocha FN, Guapo GL, Costa VP. Bloodaqueous barrier changes after the use of prostaglandin analogues in patients with pseudophakia and aphakia: a 6-month randomized trial. Arch Ophthalmol. 2005;123(2):186-92. https://doi.org/10.1001/archopht.123.2.186

16. Rashid S, Young LH. Progression of diabetic retinopathy and maculopathy after phacoemulsification surgery. Int Ophthalmol Clin. 2010;50(1):155-66. https://doi.org/10.1097/IO.0b013e3181c555cf

17. Kim SJ, Belair ML, Bressler NM, Dunn JP, Thorne JE, Kedhar SR, et al. A method of reporting macular edema after cataract surgery using optical coherence tomography. Retina. 2008;28(6):870-6. https://doi.org/10.1097//AE.0b013e318169d04e

18. Corrêa EP, Oliveira LFL, Serracarbassa PD, Oshima A, Castro EFS. Evaluation of macular edema after uncomplicated phacoemulsification surgery with implantation of intraocular lens by spectral domain optical coherencetomography. Arq Bras Oftalmol. 2013;76(6):357-62 https://doi.org/10.1590/S0004-27492013000600008 
19. Torron-Fernandez-Blanco C, Ruiz-Moreno O, Ferrer-Novella E, Sánchez-Cano A, Honrubia-Lopez FM. Edema macular quístico pseudofáquico: Detección mediante «optical coherence tomography». Arch Soc Esp Oftalmol. 2006;81(3):147-54.

20. Ching HY, Wong AC, Wong CC, Woo DC, Chan CW. Cystoid macular oedema and changes in retinal thickness after phacoemulsification with optical coherence tomography. Eye (Lond). 2006;20(3):297-303. https://doi.org/10.1038/sj.eye.6701864

21. Lobo CL, Faria PM, Soares MA, Bernardes RC, Cunha-Vaz JG. Macular alterations after small-incision cataract surgery. $\mathrm{J}$ Cataract Refract Surg. 2004;30(4):752-60 https://doi.org/10.1016/S0886-3350(03)00582-0

22. Perente I, Utine CA, Ozturker C, Cakir M, Kaya V, Eren $\mathrm{H}$, et al. Evaluation of macular changes after uncomplicated phacoemulsification surgery by optical coherence tomography. Curr Eye Res. 2007:32(3):241-7. https://doi.org/10.1080/02713680601160610

23. Daien V, Korobelnik JF, Delcourt C, Cougnard-Gregoire A, Delyfer $\mathrm{MN}$, Bron $\mathrm{AM}$, et al. French medical-administrative database for Epidemiology and Safety in Ophthalmology (EPISAFE): the EPISAFE collaboration program in cataract surgery. Ophthalmic Res. 2017;58(2):67-73.

https://doi.org/10.1159/000456721

24. Shah AS, Chen SH. Cataract surgery and diabetes. Curr Opin Ophthalmol. 2010;21(1):4-9.

https://doi.org/10.1097/ICU.0b013e328333e9c1

25. Chen XY, Song WJ, Cai HY, Lin Z. Macular edema after cataract surgery in diabetic eyes evaluated by optical coherence tomography. Int J Ophthalmol. 2016;9(1):81-5. https://doi.org/10.18240/ijo.2016.01.14

26. Kim BY, Smith SD, Kaiser PK. Optical coherence tomographic patterns of diabetic macular edema. Am $J$ Ophthalmol. 2006;142(3):405-12.

https://doi.org/10.1016/i.ajo.2006.04.023

27. Biro Z, Balla Z, Kovacs B. Change of foveal and perifoveal thickness measured by OCT after phacoemulsification and IOL implantation. Eye Lond. 2008;22(1):8-12. https://doi.org/10.1038/sj.eye.6702460 